\title{
LEGAL ISSUES \& LANGUAGE LEARNING TECHNOLOGY
}

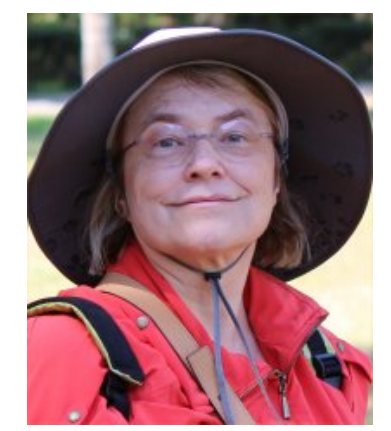

Judy Shoaf

University of Florida

\section{The Georgia State Case}

In my last column I discussed a lawsuit dismissed by a judge in October 2011. That case, touching the large-scale streaming of video by UCLA, was poorly formulated; the wrong plaintiff was suing the wrong defendants, and issues of Fair Use fell by the wayside. Now, however, in May 2012, a federal judge, in a 350-page decision, carefully examines the concept of Fair Use in education. For the first time educators have judicial guidance in putting copyrighted materials online for their students. ${ }^{1}$

\footnotetext{
${ }^{1}$ Kevin Smith of Duke offers a summary: http://blogs.library.duke.edu/scholcomm/2012/05/12/. See also the analysis of the American Association of Publishers, http://www.publishers.org/press/66/ which links to Oxford University Press's and Sage Publications' (identical) statements.
} 
This case was brought in the United States District Court for the Northern District of Georgia by plaintiffs Cambridge and Oxford University Presses and Sage Publications, against defendants at Georgia State University. The allegation was that the digital course reserve operated by the university library was giving students digital copies of texts published by the plaintiffs, thus violating copyright. As with UCLA, the university decided to defend its practices as Fair Use. ${ }^{2}$ The case came to trial in May 2011 has now been decided, largely in favor of the defendants, by Judge Orinda D. Evans.

Judge Evans found in favor of the plaintiffs in only 5 of the $75^{3}$ infringement claims (\#11,\#16,\#22,\#71, and \#73). Many claims were inadequately documented or easily dismissed. In 47 claims, however, some violation of copyright had taken place. The judge analyzed the circumstances in each of these claims with respect to Fair Use, and she found 42 of them to consist of Fair Use.

Fair Use (Section 107 of copyright law) is the backbone of educational limitations to the rights of owners: "the Fair Use of a copyrighted work, including such use by reproduction in copies or phonorecords or by any other means..., for purposes such as criticism, comment, news reporting, teaching (including multiple copies for classroom use), scholarship, or research, is not an infringement of copyright." ${ }^{4}$ Fair Use allows a citizen, or an institution, to quote, copy, or otherwise use a copyrighted item without asking permission (or paying a royalty).

Congress re-emphasizes the importance of teaching in another part of copyright law, Section 110-1, which allows just about any use of media during an actual brickand-mortar classroom session. (This is a precious right, which is not granted to educators in, for example, Canada.) The TEACH act (110-2) extends this use into the digital realm, by allowing teachers to make digital copies of classroom materials available online, in "reasonable and limited portions ... comparable to that which is typically displayed in the course of a live classroom session."

\footnotetext{
${ }^{2}$ Both Georgia State and UCLA cited the doctrine of sovereign immunity (states cannot be sued for federal crimes). This was not discussed in the UCLA dismissal, but in the Georgia State case Judge Evans commented that this defense was invalid: http://www.infodocket.com/wp-content/uploads/2012/05/GA-State-Opinion.pdf, p. 18. As was also the case at UCLA, the complaint about copyright violation at Georgia State led to development of stronger Fair Use guidelines for professors requesting that materials be made available to students (p. 2). Further citations of the opinion are by page number or claim number.

${ }^{3}$ Originally 99 examples were proposed by the 3 presses, but post-trial only 75 remained. 74 claims are analyzed in the decision. Of these, 27 did not qualify as "prima facie" copyright violations, either because the plaintiffs could not document their rights in the works involved or because the use was so minimal (students never accessed the text) that it did not constitute infringement. In 2 more claims, only part of the excerpt copied was considered, because the publishers could not document their title to the rest.

${ }^{4}$ See both section 107 and 110 at http://www.copyright.gov/title17/92chap1.pdf.
} 
But Judge Evans did not cite Section 110. The Georgia State electronic course reserves are not a function of face-to-face teaching or a virtual classroom. This case instead goes back to Basic Books vs. Kinko's (1991), and Princeton University Press vs. Michigan Document Services (1996). In both these cases, publishers sued copy services which were compiling, at the request of professors, coursepacks consisting of excerpts from various copyrighted print sources. Section 107's Fair Use was at issue. The publishers won.

In the Georgia State case, no for-profit business is involved. Rather, "an excerpt from the [title in question] was used by a nonprofit educational institution for the nonprofit, educational purposes of teaching and scholarship. Free copies were provided for the exclusive use of students, free of charge, in [a specific] class." Judge Evans asserted that the complete absence of profit in the university's practices makes this case quite different from the earlier ones (p. 49).

Whether something counts as Fair Use depends on four factors specified in Section 107, which will balance uniquely in each case:

(1) the intention (including an intention to profit);

(2) the nature of the copyrighted work;

(3) the amount and substantiality of the portion used;

(4) the effect upon the potential market for or value of the copyrighted work.

Judge Evans found that in every example she analyzed, factor 1 was strongly in favor of the defendants (Georgia State). Factor 2 was also in their favor, since all the claims involved "informational" works (creative works have stronger claims to copyright protection). Whether the use could be considered an unfair violation of copyright, then, depended on factors 3 and 4 . In the 5 claims where infringement was found, factor 3 favored the plaintiffs and factor 4 strongly favored the plaintiffs, balancing the first two factors exactly. ${ }^{6}$ Thus an "even score" on the factors led to a decision for the plaintiffs.

For factor 3, the judge set a limit for the amount considered safe or "distinctly small": $10 \%$ of a book which has fewer than 10 chapters, or one chapter of a book

\footnotetext{
${ }^{5}$ This wording is used in, I think, all the analyses of Fair Use in the decision.

${ }^{6}$ In two claims, \#14 and \#20, where factors 3 and 4 both favored the plaintiff, the Judge nevertheless decided that factor 4 did not strongly favor the plaintiff because the income from permissions for these works was so small. In those claims, the Judge decided in favor of the defendants.
} 
which has more than 10 chapters. (In a book with chapters of varying lengths, then, Fair Use might be limited to a chapter comprising much less than $10 \%$ of the total, or could exceed $10 \%$.) Collections of essays edited together as a volume are considered books for this purpose, with each essay a chapter. This is the first time a judge has given quantitative guidelines on Fair Use for educators. ${ }^{7}$

In 13 claims, the amounts copied exceeded the "distinctly small" criterion. A two-chapter excerpt posed a special problem because those chapters were the substance or "heart" of the book (\#72), and another excerpt, exceeding $20 \%$ of the book, was "a large amount" (\#51). In these two claims factor 3 was strongly in favor of the plaintiffs.

Factor 4, the effect on the market value of the copyrighted work, favors the plaintiffs "where excerpts are reasonably available, at a reasonable price." In about $2 / 3$ of the claims, the plaintiffs proved that they derived income from selling digital excerpts or permissions of the books in question. In the other claims, though, "Defendants prevail on factor four when there is no proof of a ready market for electronic excerpts of the work because there is no avenue through which Defendants could obtain permission to post excerpts of the work ... with reasonable ease." In other words, if a buyer cannot conveniently purchase the product in question (permission to copy), it cannot be considered to be for sale, and no seller has been harmed.

This decision offers real guidance both for publishers and for educators. It is to be expected that publishers will rush to make permissions more easily obtainable. They may also favor books with many short chapters over books with a few long ones. For institutions and professors, policies for using excerpts from copyrighted books will be much easier to formulate, though each example requires considering factors 2, 3, and 4, which will vary. The rule- $10 \%$ of a book with fewer than 10 chapters, or 1 chapter from a book with more than 10 chapters-provides a clear cut-off point; if one wants to use more of a book, one should seek permission.

Of course, for us language teachers, the question remains: how does this ruling apply to audio and video materials? I subscribe to an email discussion list for video librarians and vendors (Vidlib) and the reaction there has been intense; the first consensus seems to be that a " $10 \%$ rule" would apply to any copyrighted work, not

\footnotetext{
${ }^{7}$ In 1976, "Classroom Guidelines" were developed by a committee of publishers and educators, under the aegis of Congress, the "Agreement on Guidelines for Classroom Copying in Not-For-Profit Educational Institutions with Respect to Books and Periodicals," http://copyright.cornell.edu/policies/multiple-copies-for-classroomuse.cfm. Although these had been referred to by the judges in the Kinko's and Michigan Documents case, Judge Evans found them incompatible with Section 107 (p. 59).
} 
just to books. I think that, for librarians and teachers but also for video distributors, it would be a great relief to be able to define Fair Use simply by the percentage of total minutes in a film. The new ruling will be studied in formulating school policies for posting audio and video. But Judge Evans herself does not look beyond the scholarly books discussed in the Georgia State case (and, as I have tried to make clear, there is no simple $10 \%$ rule). Other criteria will need to be developed for other media. ${ }^{8}$

Moreover, the case does not touch the special permissions for face-to-face teaching proposed in Section 110 of the law, which extend Fair Use and, as I noted earlier, are peculiar to U.S. law. Judge Evans confined herself to Section 107, though she used the phrase "multiple copies for classroom use" to apply to the electronic reserves (e.g. p. 87), thus to some extent making the library and its servers an extension of the classroom. ${ }^{9}$ The line between the virtual educational environment (Section 107) and the virtual version of the brick-and-mortar classroom (Section 110) remains ill-defined.

\section{About the Author}

Judy Shoaf has a Ph.D. in French and Medieval Literature from Cornell. She has directed the Language Learning Center at the University of Florida since 1993. She maintains a website on copyright law \& educational media that can be accessed at http://www.clas.ufl.edu/llc/Copyright.

\section{About The Column}

Legal Issues \& LLT is a column dedicated to examination of the legal considerations of copyright, fair use and ownership within the context of language teaching and learning.

\footnotetext{
${ }^{8}$ Note that it took 36 years, from the 1976 copyright law and Classroom Guidelines, to develop print media criteria....

${ }^{9}$ Judge Evans notes that "students do use the downloaded copies in the classroom," either on laptops or as printouts (p. 41). 